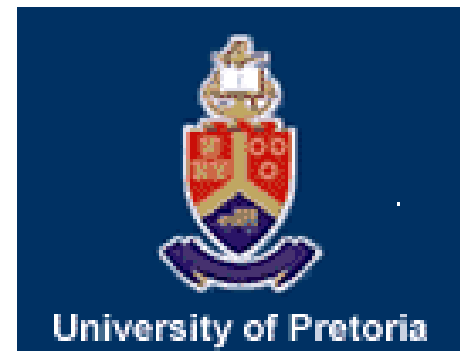

\title{
South Africa's Electricity Consumption: A Sectoral Decomposition Analysis
}

\author{
R. Inglesi-Lotz and J. Blignaut
}

Working paper 203

February 2011 


\title{
South Africa's Electricity Consumption: A Sectoral Decomposition Analysis
}

\author{
R. Inglesi-Lotz*and J. Blignaut ${ }^{\dagger}$ \\ February 15, 2011
}

\begin{abstract}
South Africa's electricity consumption has increased sharply since the early 1990s. Here we conduct a sectoral decomposition analysis of the electricity consumption for the period 1993 to 2006 , to determine the main drivers of this increase. The results show that the increase was due mainly to output- or production-related factors, with structural changes playing a secondary role. While there is some evidence of efficiency improvements, indicated here as a slowdown in the rate of increase in electricity intensity, it was not nearly sufficient to offset the combined production and structural effects that propelled electricity consumption higher.
\end{abstract}

\section{Introduction}

South Africa took the bold step at the beginning of 2010 to commit itself to the Secretariat of the United Nations Framework Convention on Climate Change (UNFCCC). This requires taking all the necessary actions to decrease the country's greenhouse gas emissions by $34 \%$ to below the "business-as-usual" scenario by 2020 (Winkler et al. 2010). The bulk of the country's greenhouse gas emissions (more than 60\%) originate from the electricity generation sector, which is heavily dependent on coal-fired power stations (Blignaut et al. 2005). Reduced electricity usage is therefore essential for scaling back on greenhouse gas emissions.

To achieve such a reduction in the use of electricity, it is imperative to understand the underlying factors which led to the historic increases in electricity consumption. Historically, studies for both developed and developing countries (Andrade Silva \& Guerra 2009; Weber 2009; Metcalf 2008; Ang \& Liu 2001; Schipper et al. 1997) have indicated that there are principally three main factors behind the rate of increase in electricity consumption. These are production changes, changes in the structure of the economy and efficiency improvements, the latter measured as the change in electricity intensity.

In this study, we conduct a decomposition analysis to determine the significance of each of these three factors. We first consider the annual changes in the contribution of the factors to total electricity consumption, followed by a sectoral decomposition analysis for the period 1993 to 2006 . This period has been selected to coincide with the post-apartheid period up until the latest available figures. If there are significant differences in the electricity consumption profile of the various sectors and in the underlying drivers for growth, a need for sectoral electricity reduction policies is indicated.

Section 2 of this paper discusses South African electricity consumption and economic growth for the period 1993 to 2006. The research method and data characteristics are discussed in Sections 3 and 4, respectively. In Section 5, the results of the decomposition analysis are presented and Section 6 concludes the study.

\footnotetext{
*Department of Economics, University of Pretoria, South Africa. Corresponding author. Email: Roula.inglesi@up.ac.za, Tel +27 (0) 124204504.

${ }^{\dagger}$ Department of Economics, University of Pretoria, South Africa.
} 


\section{Background}

South Africa is the African continent's main producer of electricity, generating $43 \%$ of the total electricity in 2007 (Amusa et al. 2009; Odhiambo 2009). Amusa et al. (2009) show that 92\% of electricity produced by Eskom (the national electricity provider) is produced from coal, with the remainder generated from nuclear energy $(5 \%)$ and other sources $(3 \%)$. This contributed to the country's high carbon emissions intensity (Blignaut et al. 2005), which has to be reduced to meet international commitments made.

Since the beginning of the 1990s and especially from 1994 onwards, after the democratisation of the country, the South African economy and society have undergone major structural changes. Directly as a result of apartheid policies, poor rural areas suffered from, among others, a lack of access to basic services such as electricity. Almost two-thirds of the South African population did not have access to electricity before 1994 (Ziramba 2008). In addition, the new (post-1994) South African government considered electricity provision as very important for the growth and development of the country (DME 2003; RSA 2006). It is, therefore, not surprising that the demand for electricity since then has followed the country's economic growth path very closely (see Figure 1).

Take Figure 1

A closer analysis, however, is required to unpack this trend. One way of doing so is by gaining an understanding of the sectoral differences as depicted through the electricity intensities, and to then conduct a decomposition analysis to determine the main factors that have determined this growth in electricity consumption. We turn to this next.

\section{Research method}

The decomposition technique as an analytical tool has attracted much interest in the energy literature over the past two decades (Sun 1998; Ozawa et al. 2002; Markandya et al. 2006; Korppoo et al. 2008; Metcalf 2008; Liddle 2009; Andrade Silva \& Guerra 2009; Zhou 2010; Mendiluce et al. 2010; Zhao et al. 2010). The decomposition of energy ( sic. electricity) consumption is not unlike the use of indices to investigate the contribution of changes in quantity and price to changes in aggregate consumption (Mendiluce et al. 2010). Decomposition analysis is employed to separate changes in electricity consumption over time into mainly three driving factors, namely i) changes in the structure of the economy, ii) changes in efficiency and/or iii) production changes (Andrade Silva \& Guerra 2009; Weber 2009; Metcalf 2008; Ang \& Liu 2001; Schipper et al. 1997).

There are primarily two types of decomposition methodologies, namely the index decomposition analysis (IDA) (Zhao et al. 2010; Salta et al. 2009; Korppoo et al. 2008) and the structural decomposition analysis (SDA) (Wachsmann et al. 2009). The main difference between these two methods is that SDA can explain indirect effects of the final demand by dividing an economy into different sectors and commodities, and examining the effects on them individually (Wachsmann et al. 2009), while IDA explains only direct (first-round) effects to the economy. The IDA applies sectoral production and electricity and the SDA requires data-intensive energy input-output analysis (Weber 2009). The advantages and constraints of each of these methods are discussed in depth by Hoekstra and Van den Bergh (2003) and Ma and Stern (2008). Because of the data constraint concerning SDA, the IDA is generally perceived as the method of choice by a number of studies (Liu \& Ang 2007; Ang 2004; Ang \& Zhang 2000).

Following this tradition we also deploy the IDA method. Among the practitioners of the IDA method there are differences concerning the appropriate indexing method. We, however, concur with Mendiluce et al. (2010), Ang and Liu (2001), Ang (2004) and Ang and Zhang (2000) that the multiplicative and additive Log Mean Divisia Index method (LMDI) should be the preferred method for the following reasons:

- It has a solid theoretical foundation; 
- Its adaptability

- Its ease of use and result interpretation;

- Its perfect decomposition;

- There is no unexplained residual term; and

- Its consistency in aggregation.

Another feature of the LMDI decomposition method is that it presents symmetry between decomposition of changes in terms of ratios or differences (Choi \& Ang 2003), which means that decomposition in ratios or differences gives the same results. Given the above rationale, and international usage, we use the LMDI method in the same way as Zhao et al. (2010). The variables and terms to be used are defined as follows:

- $\mathrm{E}_{t}$ : total Industrial \& Agriculture electricity consumption in year $t$

- $\mathrm{E}_{i t}$ : electricity consumption in sector $i$ in year $t$

- $\mathrm{Y}_{t}$ : total Industrial \& Agriculture output in year $t$

- $\mathrm{Y}_{i t}$ : output of sector $i$ in year $t$

- $\mathrm{S}_{i t}$ : output share of sector $i$ in year $t(=\mathrm{Y} i, t / \mathrm{Y} t)$

- $\mathrm{I}_{i t}$ : electricity intensity of sector $i$ in year $t(=\mathrm{E} i, t / \mathrm{Y} i, t)$

Total Industrial \& Agriculture electricity consumption:

$$
E_{t}=\sum_{i} Y_{t} \frac{Y_{i t}}{Y_{t}} \frac{E_{i t}}{Y_{i t}}=\sum_{i} Y_{t} S_{i t} I_{i t}
$$

Change in total Industrial \& Agriculture electricity consumption between year 0 and year $t$ :

$$
\triangle E_{\text {tot }}=E_{t}-E_{0}=\Delta E_{\text {out }}+\triangle E_{i, s t r}+\triangle E_{\text {int }}
$$

where out denotes change in real output, str denotes structural change and int denotes intensity change, which equates to changes in efficiency. For each of the sectors, the following holds:

$$
\triangle E_{i}=E_{i . t}-E_{i, 0}=\Delta E_{i, \text { out }}+\Delta E_{i, \text { str }}+\triangle E_{i, \text { int }}
$$

Based on the approach followed by Ang (2004) and Zhao et al. (2010), the above-mentioned changes are defined as follows:

$$
\begin{gathered}
\triangle E_{\text {out }}=\sum_{i} w_{i t} 1 n\left(\frac{Y_{t}}{Y_{0}}\right) \\
\triangle E_{\text {str }}=\sum_{i} w_{i t} 1 n\left(\frac{S_{i t}}{S_{0}}\right) \\
\triangle E_{\text {int }}=\sum_{i} w_{i t} 1 n\left(\frac{I_{i t}}{I_{0}}\right) \\
\triangle E_{\text {tot }}=E_{t}-E_{0}=\sum w_{i t} 1 n\left(\frac{Y_{t} S_{t} I_{i t}}{Y_{0} S_{i 0} I_{i 0}}\right)
\end{gathered}
$$

Where $w$ is the logarithmic weighting scheme: 


$$
w_{i t}=L\left(E_{i t}-E_{i 0}\right)=\frac{E_{i t}-E_{i 0}}{1 n\left(\frac{E_{i t}}{E_{i 0}}\right)}
$$

and

$$
L(x, y)={ }^{(y-x)} / \ln (y / x), x \neq y
$$

The production effect being equal to the "change in production" is self-explanatory. The structural effect, however, is equal to the "change in sectoral share" and one could argue that the sum total of this effect should be zero. It should be noted, though, that the structural effect is not a simple summation, but is a summation of the weighted changes (as is also the case for the production and efficiency effects) and hence the total is not equal to zero. For example, if the proportions of electricity-intensive sectors increased relative to those of less electricity-intensive sectors, the structural effect will be positive and hence the economic system will be considered more electricity intensive. Lastly, the efficiency effect (also called either the intensity or technology effects in the literature) refers to the change in the level of intensity. A change in the efficiency effect therefore refers to the weighted change in the level of electricity intensity.

\section{Data sources and characteristics}

African countries suffer from a dearth of energy data. South Africa, for example, started reporting official energy balances only from 1993 onwards. Therefore, the study period selected is from 1993 to 2006 and the sectoral data on electricity consumption and real output are collected accordingly. The study period was selected based upon data restrictions and also to avoid capturing abnormalities from the period before the country's democratisation, which happed over the period 1990-1994.

The selection of sector-level disaggregation is mainly focussed on the primary and secondary sectors due to the nature of the economy. We therefore place more emphasis on the agricultural, mining and industrial sectors than on the pure service-orientated sectors. The government and household sectors are not included in the analysis. The government's output is considered to be its expenditure and this is highly influenced by the political agenda of the government of the day. As for household expenditure, there is not a specific indicator for its output. The residential electricity consumption profile is also not comparable with the country's economic sectors.

Data on real output per sector was collected from the Quantec Standardised Industry Database (www.quantec.co.za/data/easydata-rsastandardised-industry) and the data for electricity consumption from the Aggregate Energy Balances of the Department of Minerals and Energy (DME; various issues). All economic measures are reported as rand millions (constant 2005 prices) and the electricity consumption is measured in GWh.

\section{$5 \quad$ Results}

The results of the decomposition analysis are provided in Table 1. It shows, among others, the large increase in the electricity consumption in South Africa from 1993 to 2006, which amounts to a total increase of 131,024 GWh. As expected for an economy that started growing rapidly the last two decades, the dominant force driving electricity consumption is the output changes. The output effect is responsible for $152,364 \mathrm{GWh}$ (or 116\%) of the total increase in electricity consumption. This effect is to be understood in the light of the fact that South Africa has undergone major political, social and economic changes during the period, resulting in a sharp increase in economic activity. Furthermore, the structural changes (changes in the contribution of each sector to the total output of the economy) in the economy also contributed to the increase in electricity consumption $(98,220$ or $64 \%$ ). See Table 1 below. 
In contrast, and as expected, the efficiency effect (change in the level of electricity intensity) was the only factor contributing to a decreasing in electricity consumption. Although both electricity consumption and total output increased substantially over the study period, raising the overall electricity intensity of the country, the rate of increase is declining. The declining rate of increase is considered to be due to efficiency improvements.

The efficiency improvements contributed a decrease of 119,560 GWh in the total change. This implies that, if it were not for the slowdown in the increase in electricity intensity, electricity consumption would have been higher by about $120,000 \mathrm{GWh}$ - or $120 \mathrm{TWh}$ (Table 1). The overall effects of the two factors for the period 1993 to 2006 are illustrated in Figure 2 below.

The positive but declining growth rate of efficiency indicates that the South African economy could be approaching the top of the electricity environmental Kuznets curve. While this is still unconfirmed, we can state that achieving a certain level of income growth is not sufficient to improve the total electricity efficiency levels. To accomplish such a goal, appropriate policies and institutions should be in place (Yandle et al. 2002), which would require knowing and taking into account the contributing factors of electricity usage and the position of the country in the environmental Kuznets curve. More importantly, our results show the significance of technological improvements for electricity demand. The efficiency effect (or technology effect) is the only factor that contributes to downward pressure on the electricity consumption. This is because the technology effect can work in either of two ways (or a combination thereof), namely, i) technological progress can motivate consumers to switch to cost-effective and cleaner forms of energy, and/or ii) it could encourage them to decrease their electricity usage. Policy makers should, therefore, implement appropriate policies to promote technological progress and the use of cleaner forms of energy.

These results are in accordance with findings for China (Zhao et al. 2010). Their results show that efficiency improvements are the only factor that contributes towards downward pressure on electricity consumption. This effect, however, is not enough to offset completely the high contribution of the production and structural changes that push up the demand for electricity.

These results differ from a number of other studies. Studies for developed economies (Sinton and Levine, 1994; Zhang, 2003) conclude that efficiency improvements are the most influential factor in economy-wide electricity consumption. The results for South Africa, however, show that the production effect is the main factor driving demand for electricity higher. Even though South Africa is an emerging economy that has seen much political change over the last two decades, the structural effect was not a dominant factor, on the contrary to other developing countries were the structural changes were the main contributor (Smil, 1990; Kambara, 1992).

To gain further insight into the trends of electricity consumption, one has to turn from a nationallevel analysis to a sectoral one. This is since no two sectors have the same electricity consumption profile and economic activity levels (Inglesi \& Blignaut 2010). This exercise is useful in identifying the dominant economic sectors that determine South Africa's electricity consumption trend and in specifying the importance of each of the factors responsible for this trend per sector.

In Table 2 we present the results of a sectoral decomposition analysis. In the table the sectors are organised according to their efficiency effect, with the sector in which efficiency improvements in absolute terms was the highest listed first. In the last column, sector ranking with regards to their aggregate effect on electricity consumption for the period 1993 to 2006 is provided.

The majority of the sectors, with the exception of 'mining and quarrying', 'wood and wood products', 'machinery' and 'textiles and leather', have experienced an increase in their electricity consumption from 1993 to 2006 . The top three contributors to national electricity consumption were 'non-ferrous metals' (14,089 GWh), 'iron and steel' (13,027 GWh) and 'chemical and petrochemical' $(8,449 \mathrm{GWh})$. Increases in production are part of the rising electricity usage in all sectors of the South African economy. 'Iron and steel', 'transport' and 'non-ferrous metals' are responsible for $40 \%$ of the total production effect.

As far as the second-most important driving factor of electricity consumption - i.e. efficiency improvements - is concerned, it has played a role in only five out of fourteen sectors in the reduction 
of electricity consumption ('transport', 'iron and steel', 'mining and quarrying', 'wood and wood products' and 'machinery'). However, 'non-ferrous metals', that contributed much to the aggregate effect (i.e. contribution to electricity consumption), is the one that presented the highest positive efficiency effect, i.e. a worsening of efficiency (3,572 GWh). From this it is clear that even though the national, economy-wide, effects shown in Table 1 indicate a slowdown in the rate of increase in electricity intensity, and hence efficiency improvements, that this effect is not a country-wide phenomena. It is highly sector specific. The efficiency effect is dominated by the 'transport', 'iron and steel' and 'mining' sectors. This warrants closer scrutiny.

In the transport sector, one of the main electricity users during the early part of the study period was freight rail. This sector all but collapsed during the study period, with freight transport being shifted to road and long haul. This implies that electricity consumption by the sector declined significantly; meanwhile, output/production did not decline. This suggests that the South African transport sector experienced a switch from electricity to other forms of energy, such as oil/petroleum. The efficiency effect reported here therefore is not necessarily that of improved use of electricitybased transport, but a change in transport mode, i.e. a technology change. It is therefore not a bona fide efficiency improvement.

The 'iron and steel' sector presents an efficiency effect of $6031 \mathrm{GWh}$ for the studied period. This finding is the result of an economic change rather than a technology or efficiency change, per se. The overall output of the sector has increased by $143.5 \%$ for the period from 1993 to 2006, while the demand for electricity increased by $70 \%$ for the same period. While this might seem like an efficiency effect, the reality is that the price-formation process within the iron and steel sector has changed during the study period. Whereas South Africans enjoyed the benefit of having relatively cheap locally produced steel during the early part, the country was faced with steel price increases during the latter part, as the industry moved towards exchange rate linked (export-party) prices.

The mining sector also provides a unique example. During the period under investigation the mines engaged in a process of co-generation, whereby they started to generate their own electricity, or by creating smaller power units (www,iol.co.za, 2010). Hence, their electricity demand from the national supplier has declined.

The structural change was a negative contributor to the electricity usage of a number of sectors (eight out of fourteen). However, it contributed towards the increase in electricity consumption by the largest electricity consumers, such as 'transport' (6,805 GWh), 'iron and steel' (4,291 GWh) and 'non-ferrous metals' (1,683 GWh).

\section{Conclusion}

This study examines electricity consumption in South Africa for the period 1993 to 2006. The purpose of the analysis is to identify factors that led to the increasing levels of electricity consumption for the period. To do so, decomposition techniques were applied in order to break down the consumption into three main factors: the changes in production, structural changes of the economy and efficiency improvements.

Our findings show that electricity consumption is affected mostly by output changes, followed by efficiency improvements and, lastly, by structural changes. Also, their contribution to electricity consumption trends increased through the years. From the period 1993-94 to 1996-97 (see Table 1), changes in the structure of the economy considerably influenced the increase in electricity consumption. From the following year, the efficiency improvements contributed more towards the decreasing side of the consumption. Until the end of the period, intensity has shown its decreasing influence (lower than production effects) to the electricity consumption trend.

Although these findings present an important trend, examination of the factors that affected each economic sector separately would provide useful information for South African energy-policy makers. Firstly, through a sectoral-decomposition exercise, dominant electricity consumption sectors 
can be identified. The top three contributors to national electricity consumption were 'non-ferrous metals' (14,089 GWh), 'iron and steel' (13,027 GWh) and 'chemical and petrochemical' (8,449 GWh). Increases in production are proven to be part of the rising electricity usage in all the sectors of the South African economy, with 'iron and steel', 'transport' and 'non-ferrous metals' being the main contributors to the effect.

On the decreasing side of electricity consumption, only five out of fourteen sectors were affected substantially by efficiency improvements while, for the rest, efficiency did not assist in the reduction of consumption. However, 'non-ferrous metals', that contributed much to the aggregate effect (i.e. contribution to electricity consumption), is the one that presented the highest positive efficiency effect $(3,572 \mathrm{GWh})$.

Finally, structural economic changes did not affect electricity consumption in the same manner for all the sectors. For eight out of the fourteen sectors, it was a negative contributor, but it contributed to the rising effect of consumption for the highest electricity consumers such as 'transport', 'iron and steel' and 'non-ferrous metals'. In sum, the results show that various production sectors in the South African economy have different electricity usage profiles.

According to the decomposition analysis, the change in production was the main factor that increased electricity consumption, while efficiency improvement during the period was a driver to decrease electricity consumption. However this increase has been dominated by positive scale effect (income or production increase) and hence, it was not able to offset the influence of the output changes. This important result of the exercise is particularly useful for policy making as further improvements in efficiency are needed to intensify its decreasing influence on electricity usage.

The main aim of macroeconomic policies is an increase in the country's production. However, our results have shown that such an increase would be a contributing factor to higher the electricity demand and therefore consumption, contributing to more greenhouse gas emissions. Environmental policies, including environmental fiscal reform, should therefore aim to develop the economy on an alternative growth path, which will promote the reduction of electricity intensity and greenhouse gas emissions without compromising the welfare of the country as a whole.

According to our results, the improvement in electricity efficiency on a national level might be proven to be the desired solution towards a decrease in electricity consumption without neglecting the importance of the country's economic growth. Over the study period, the impact of efficiency improvements on electricity consumption has been outweighed by the high positive effects of changes in production. Moreover, our results show various inter-sectoral differences concerning electricity consumption. This necessitates the implementation of sector-specific strategies. For instance, based on their efficiency effects, industries such as 'non-ferrous metals' and 'chemical and petrochemical' require stricter energy efficiency policies than the 'transport' and 'iron and steel' sectors.

\section{References}

[1] Amusa, H., Amusa, K. \& Mabugu, R. 2009, "Aggregate demand for electricity in South Africa: An analysis using the bounds testing approach to cointegration", Energy Policy, vol. 37, no. 10, pp. 4167-4175.

[2] Andrade Silva, F.I. \& Guerra, S.M.G. 2009, "Analysis of the energy intensity evolution in the Brazilian industrial sector-1995 to 2005", Renewable and Sustainable Energy Reviews, vol. 13, no. 9, pp. 2589-2596.

[3] Ang, B.W. 2004, "Decomposition analysis for policymaking in energy: which is the preferred method?", Energy Policy, vol. 32, no. 9, pp. 1131-1139.

[4] Ang, B.W. \& Liu, F.L. 2001, "A new energy decomposition method: perfect in decomposition and consistent in aggregation", Energy, vol. 26, no. 6, pp. 537-548. 
[5] Ang, B.W. \& Zhang, F.Q. 2000, "A survey of index decomposition analysis in energy and environmental studies", Energy, vol. 25, no. 12, pp. 1149-1176.

[6] Blignaut, J.N., Mabugu, R.M. \& Chitiga-Mabugu, M.R. 2005, "Constructing a greenhouse gas emissions inventory using energy balances: the case of South Africa: 1998", Journal of energy in Southern Africa, vol.16, no.3, pp.105-116.

[7] Choi, K.H. \& Ang, B.W. 2003, "Decomposition of aggregate energy intensity changes in two measures: ratio and difference", Energy Economics, vol. 25, pp.615-624.

[8] Department of Minerals and Energy. 2003, Electricity basic services support tariff (free basic electricity) policy, Department of Minerals and Energy (DME), Pretoria, South Africa.

[9] Department of Minerals and Energy. DME Various issues, Aggregate Energy Balances, Department of Minerals and Energy (DME), Pretoria, South Africa.

[10] Hoekstra, R. \& van den Bergh, J.C.J.M. 2003, "Comparing structural decomposition analysis and index", Energy Economics, vol. 25, no. 1, pp. 39-64.

[11] Inglesi, R. \& Blignaut, J. 2010, "Estimating the demand elasticity for electricity by sector in South Africa", Putting a price on carbon: Economic instruments to mitigate climate change in South Africa and other developing countries. Energy Research Center, University of Cape Town, pp. 65.

[12] IOL. 2010, "Electricity co-generating growing", Available at: http://www.iol.co.za/business/markets/south-africa/electricity-co-generation-growing1.837757

[13] Kambara, T. 1992, "The energy situation in China", China Q. vol. 131, pp. 608-636.

[14] Korppoo, A., Luukkanen, J., Vehmas, J. \& Kinnunen, M. 2008, "What goes down must come up? Trends of industrial electricity use in the North-West of Russia", Energy Policy, vol. 36, no. 9 , pp. 3588-3597.

[15] Liddle, B. 2009, "Electricity intensity convergence in IEA/OECD countries: Aggregate and sectoral analysis", Energy Policy, vol. 37, no. 4, pp. 1470-1478.

[16] Liu, N. \& Ang, B.W. 2007, "Factors shaping aggregate energy intensity trend for industry: Energy intensity versus product mix", Energy Economics, vol.29, no.4, pp. 609-635.

[17] Ma, C. \& Stern, D.I. 2008, "China's changing energy intensity trend: A decomposition analysis", Energy Economics, vol. 30, no. 3, pp. 1037-1053.

[18] Markandya, A., Pedroso-Galinato, S. \& Streimikiene, D. 2006, "Energy intensity in transition economies: Is there convergence towards the EU average?", Energy Economics, vol. 28, no. 1, pp. 121-145.

[19] Mbendi. Online. "Iron and steel manufacturing in South Africa- Overview". Available at: http://www.mbendi.com/indy/mnfc/irns/af/sa/p0005.htm.

[20] Mendiluce, M., Pérez-Arriaga, I. \& Ocaña, C. 2010, "Comparison of the evolution of energy intensity in Spain and in the EU15. Why is Spain different?", Energy Policy, vol. 38, no. 1, pp. 639-645.

[21] Metcalf, G.E. 2008, "An Empirical Analysis of Energy Intensity and Its Determinants at the State Level", The Energy Journal, vol. 29, no. 3, pp. 1-27. 
[22] Odhiambo, N.M. 2009, "Electricity consumption and economic growth in South Africa: A trivariate causality test", Energy Economics, vol. 31, no. 5, pp. 635-640.

[23] Ozawa, L., Sheinbaum, C., Martin, N., Worell, E. \& Price, L. 2002, "Energy use and CO2 emissions in Mexico's iron and steel industry", Energy, vol.27, pp. 225-239.

[24] Republic of South Africa (RSA). 2006, Act 4 of 2006 Government Gazette, Pretoria, South Africa.

[25] Salta, M., Polatidis, H. \& Haralambopoulos, D. 2009, "Energy use in the Greek manufacturing sector: A methodological framework based on physical indicators with aggregation and decomposition analysis", Energy, vol. 34, no. 1, pp. 90-111.

[26] Schipper, L., Ting, M., Khrushch, M. \& Golove, W. 1997, "The evolution of carbon dioxide emissions from energy use in industrialized countries: an end-use analysis", Energy Policy, vol. 25 , no. 7-9, pp. 651-672.

[27] Sinton, J.E. \& Levine, M.D. 1994, "Changing energy intensity in Chinese industry: The relative importance of structural shift and intensity change", Energy Policy, vol.22, no.3, pp. 239-255.

[28] Smil, V. 1990, China's Energy. Report Prepared for the U.S. Congress, Office of Technology Assessment, Washington, DC.

[29] South African Reserve Bank. Various issues, Quarterly Bulletin, South African Reserve Bank, Pretoria, South Africa.

[30] Sun, J.W. 1998, "Changes in energy consumption and energy intensity: a complete decomposition model", Energy Economics, vol. 20, pp. 85-100.

[31] Wachsmann, U., Wood, R., Lenzen, M. \& Schaeffer, R. 2009, "Structural decomposition of energy use in Brazil from 1970 to 1996", Applied Energy, vol. 86, no. 4, pp. 578-587.

[32] Weber, C.L. 2009, "Measuring structural change and energy use: Decomposition of the US economy from 1997 to 2002", Energy Policy, vol. 37, no. 4, pp. 1561-1570.

[33] Winkler, H., Jooste, M. \& Marquard, A. 2010, "Structuring approaches to pricing carbon in energy- and trade- intensive sectors: options for South Africa", Putting a price on carbon: Economic instruments to mitigate climate change in South Africa and other developing countries.Energy Research Center, University of Cape Town, pp. 65.

[34] Yandle, B., Vijayaraghavan, M., Bhattarai, M. 2002, "The Environmental Kuznets Curve: A primer", Property and Environment Research Center (PERC) Research study 02-1, Montana, US.

[35] Zhang, Z. 2003, "Why did the energy intensity fall in China's industrial sector in the 1990s? The relative importance of structural change and intensity change", Energy Economics, vol. 25, no. 6 , pp. $625-638$.

[36] Zhao, X., Ma, C. \& Hong, D. 2010, "Why did China's energy intensity increase during 19982006: Decomposition and policy analysis", Energy Policy, vol. 38, no. 3, pp. 1379-1388.

[37] Zhou, N., Levine, M.D. \& Price, L. 2010, "Overview of current energy-efficiency policies in China", Energy Policy, In Press, Corrected Proof.

[38] Ziramba, E. 2008, "The demand for residential electricity in South Africa", Energy Policy, vol. 36, no. 9, pp. 3460-3466. 
Table 1: Decomposition of South Africa's total electricity consumption: 1993-2006 (GWh)

\begin{tabular}{c|c|c|c|c}
\hline & $\begin{array}{c}\text { Change in electricity } \\
\text { consumption }\end{array}$ & $\begin{array}{c}\text { Production } \\
\text { effect }\end{array}$ & $\begin{array}{c}\text { Structural } \\
\text { effect }\end{array}$ & $\begin{array}{c}\text { Efficiency } \\
\text { effect }\end{array}$ \\
\hline $\mathbf{1 9 9 3 - 1 9 9 4}$ & 12,728 & 10,019 & 7,956 & $-5,248$ \\
$\mathbf{1 9 9 4 - 1 9 9 5}$ & 12,621 & 10,608 & 8,263 & $-6,250$ \\
$\mathbf{1 9 9 5 - 1 9 9 6}$ & 16,539 & 11,574 & 10,635 & $-5,670$ \\
$\mathbf{1 9 9 6 - 1 9 9 7}$ & 6,232 & 10,059 & 5,972 & $-9,799$ \\
$\mathbf{1 9 9 7 - 1 9 9 8}$ & 7,327 & 10,905 & 7,256 & $-10,833$ \\
$\mathbf{1 9 9 8 - 1 9 9 9}$ & 6,408 & 10,739 & 6,101 & $-10,432$ \\
$\mathbf{1 9 9 9 - 2 0 0 0}$ & 8,138 & 14,537 & 6,794 & $-13,193$ \\
$\mathbf{2 0 0 0 - 2 0 0 1}$ & 13,476 & 9,171 & 4,923 & -617 \\
$\mathbf{2 0 0 1 - 2 0 0 2}$ & 19,415 & 20,444 & 15,020 & $-16,049$ \\
$\mathbf{2 0 0 2 - 2 0 0 3}$ & 9,000 & 11,542 & 8,125 & $-10,667$ \\
$\mathbf{2 0 0 3 - 2 0 0 4}$ & 14,660 & 12,356 & 7,887 & $-5,583$ \\
$\mathbf{2 0 0 4 - 2 0 0 5}$ & 2,815 & 11,107 & 5,883 & $-14,174$ \\
$\mathbf{2 0 0 5 - 2 0 0 6}$ & 1,665 & 9,303 & 3,407 & $-11,045$ \\
& & & & \\
$\mathbf{1 9 9 3 - 2 0 0 6}$ & 131,024 & 152,364 & 98,220 & $-119,560$ \\
& & $116 \%$ & $64 \%$ & $-122 \%$ \\
\hline
\end{tabular}

Table 2: Decomposition of South Africa's electricity consumption by sector 1993 to 2006 (GWh)

\begin{tabular}{l|c|c|c|c|c}
\hline & $\begin{array}{c}\text { Production } \\
\text { effect } \\
9168\end{array}$ & $\begin{array}{c}\text { Structural } \\
\text { effect } \\
6805\end{array}$ & $\begin{array}{c}\text { Efficiency } \\
\text { effect } \\
\text { Transport }\end{array}$ & $\begin{array}{c}\text { Aggregate } \\
\text { effect }\end{array}$ & $\begin{array}{c}\text { Aggregate } \\
\text { Ranking } \\
(4)\end{array}$ \\
Iron and steel & 14767 & 4291 & -6031 & 13027 & $(2)$ \\
Mining and quarrying & 3081 & -16973 & -3603 & -17496 & $(14)$ \\
Wood and wood products & 248 & 6 & -437 & -183 & $(13)$ \\
Machinery & 31 & -14 & -98 & -81 & $(12)$ \\
Construction & 16 & -1 & 27 & 42 & $(10)$ \\
Textiles and leather & 85 & -199 & 45 & -69 & $(11)$ \\
Transport equipment & 31 & 13 & 56 & 100 & $(9)$ \\
Paper, pulp and print & 769 & -28 & 117 & 857 & $(7)$ \\
Food and tobacco & 200 & -142 & 192 & 250 & $(8)$ \\
Non-metallic minerals & 715 & -326 & 927 & 1316 & $(6)$ \\
Agriculture & 1563 & -1172 & 1170 & 1562 & $(5)$ \\
Chemical and petrochemical & 5082 & 1385 & 1982 & 8449 & $(3)$ \\
Non-ferrous metals & 8834 & 1683 & 3572 & 14089 & $(1)$ \\
\hline \hline Total manufacturing* & 30761 & 6667 & 326 & 37755 & \\
\hline
\end{tabular}

* It includes 'iron and steel', 'wood and wood products', 'machinery and equipment', 'textiles and leather', 'transport equipment', 'food and tobacco', 'paper, pulp and print', 'non-metallic minerals', 'chemical and petrochemical' and 'nonferrous metals'. 
Figure 1: Electricity consumption and gross domestic product (GDP) in South Africa 1993 to 2006

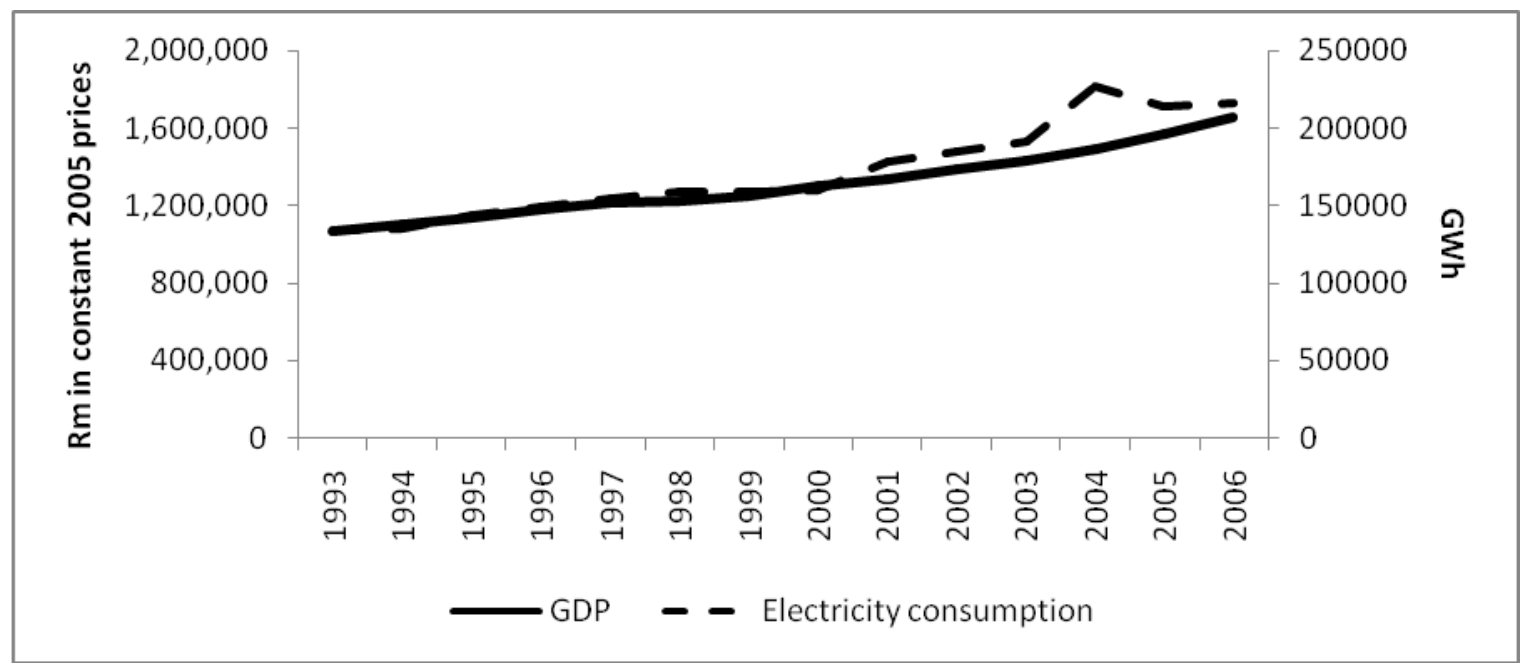

Source: South African Reserve Bank (SARB various issues) and the Department of Minerals and Energy (DME various issues).

Figure 2: Contribution of output, structural and efficiency effect to total electricity consumption for the period 1993 to 2006

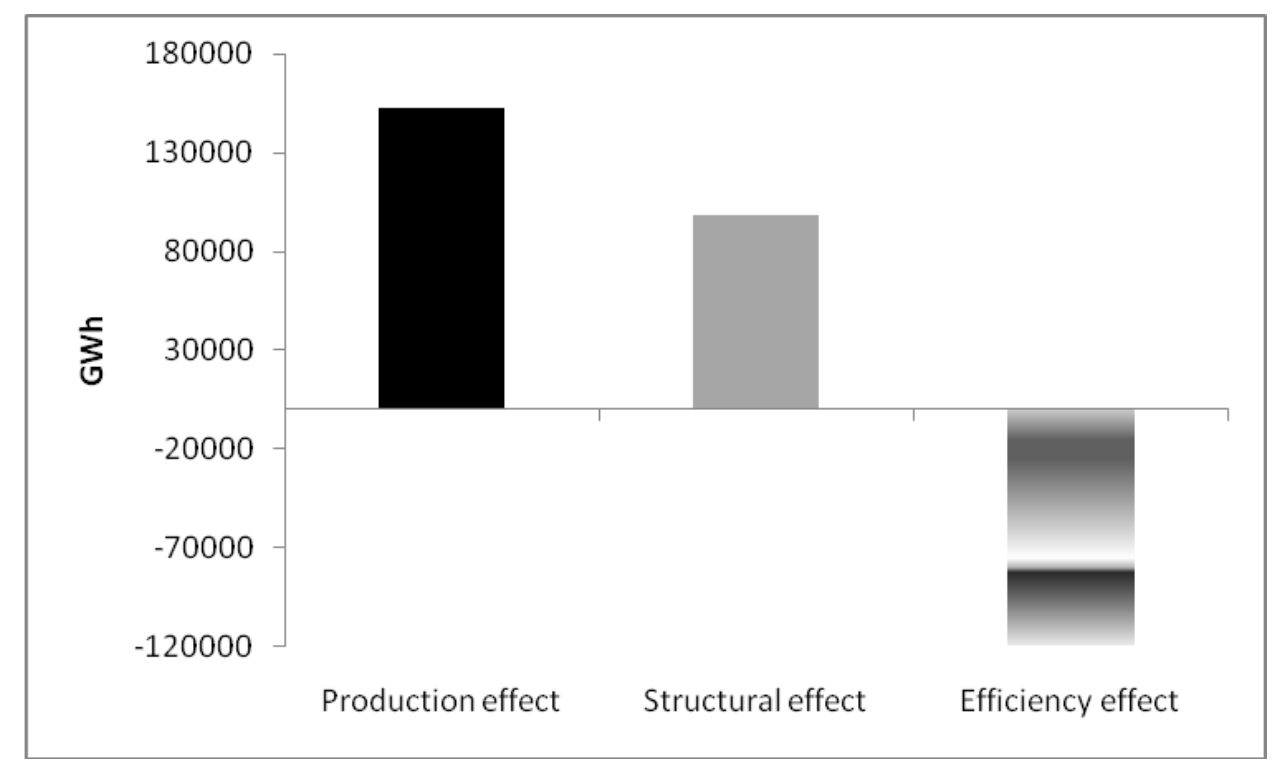

